Case Report

\title{
Foot Pad Dermatitis Associated with Osteomyelitis in a Mute Swan (Cygnus olor)
}

\author{
${ }^{1}$ Alireza Jahandideh, ${ }^{2}$ Reihaneh Manouchehri, ${ }^{2}$ Shiva Jahanshiri and ${ }^{2}$ Manely Ansari \\ ${ }^{I}$ Department of Clinical Sciences (Surgery), Faculty of Specialized Veterinary Sciences, \\ Science and Research Branch, Islamic Azad University, Tehran, Iran \\ ${ }^{2}$ Department of Clinical Sciences, Faculty of Specialized Veterinary Sciences, \\ Science and Research Branch, Islamic Azad University, Tehran, Iran
}

\author{
Article history \\ Received: 29-01-2018 \\ Revised: 9-04-2018 \\ Accepted: 04-05-2018 \\ Corresponding Author: \\ Alireza Jahandideh \\ Department of Clinical Science \\ (Surgery), Faculty of \\ Specialized Veterinary \\ Sciences, Science and Research \\ Branch, Islamic Azad \\ University, Tehran, Iran \\ Email: dr.jahandideh@gmail.com
}

\begin{abstract}
A Captive mute swan with swelling abscesses in foot pads of both legs was presented. A complete blood count reveals systemic infection. Radiographs showed radiopaque areas in foot pad of both legs and osteomyelitic periosteal reaction in left foot. After anesthesia, surgical debridement was carried out to remove pus and necrotic tissue on the plantar surface of both feet. Full surgical debridement, effective antibiotics, good post-surgical care and husbandry are affecting factors that cause no recurs of disease despite osteomyelitis.
\end{abstract}

Keywords: Mute Swan, Cygnus olor, Bumblefoot, Ostemyelitis, Staphylococcus aureus

\section{Introduction}

Mute swan originated from Europe and central Asia. This extremely elegant bird has been introduced as an ornamental species in many other parts of the world (Burnie, 2011). Adult swans are truly massive flying birds. They can be $1.6 \mathrm{~m}$ in length (half of which is neck) and can have a wingspan well in excess of $2 \mathrm{~m}$. Adult birds weight from $6 \mathrm{~kg}$ upwards. Female birds rarely overshoot $10 \mathrm{~kg}$ but an adult male may weigh up to $14 \mathrm{~kg}$ (Routh, 2000).

Foot Pad Dermatitis (FPD) or plantar pododermatitis is also recognized as bumblefoot. It refers to an inflamed and often infected lesion on the plantar surface of the foot. It is most commonly seen in raptors, but may be seen in other species. It is a disease of captivity, being rare or nonexistent in wild birds (Doneley, 2010).

Parenteral antibiotics may be necessitated if the masses grow infected, but the underlying condition will persevere because of the environmental factors (Routh, 2000). The condition has been reported in other birds, including raptors, falcons, eagle, geese, owls, gannet, penguins (Rodriguez-Lainz et al., 1997; Müller et al., 2000; Poorbaghi et al., 2012; Parsad et al., 2010; Gentz, 1996; Daoust et al., 2000; Reidarson et al., 1999) To the author's lore this is the first report of bumblefoot associated with osteomyelitis in mute swan.

FPD are usually a consociated with Staphylococcus aureus, but other bacteria containing E. coli, Pasteurella spp., Klebsiella spp., Clostridium spp., Corynebacterium spp., Bacillus spp., Diplococcus spp., Nocardia spp., Actinobacillus spp., Actinomyces spp., Aeromonas spp., Proteus spp. and Pseudomonas spp. have been interlaced. Candida spp. and Aspergillus spp. may also be included in some cases (Doneley, 2010).

\section{Case History}

A Captive mute swan weighting $8.5 \mathrm{~kg}$ with swelling abscesses in foot pads of both legs was presented to the Islamic Azad University (IAU) specialized veterinary polyclinic (Fig. 1). On physical examination the keel was difficult to palpate and the bird was found to be in good body condition but a little bit depressed. The swollen abscesses cause inability to walk in the swan. Cloacal temperature was $40^{\circ} \mathrm{C}$ and dehydration was not remarkable.

A complete blood count reveals systemic infection with an increase in leukocytes (heterophilia, monocytosis accompanied with lymphopnea). Radiographs of both legs obtained. These showed radiopaque areas in foot pad of both legs and osteomyelitic periosteal reaction in left foot (Fig. 2).

Anesthesia was induced with xylazine $2 \%(0.3 \mathrm{mg} / \mathrm{kg}$ Alfasan, Netherlands) and ketamine 10\% (12 mg/kg Alfasan, Netherlands) intravenously. Then swan intubated with a cuffed endotracheal tube and a single 
dose of atropine $\left(0.04 \mathrm{mg} / \mathrm{kg}\right.$ Dicatro ${ }^{\circledR}$, Caspian Co., Iran) injected intramuscularly to make sure that the tube does not become blocked with tracheal secretions. Isoflurane (5\%) used for inhalation anesthesia.

Surgical plan to amputate osteomyelitic bone recommended, but owner refused amputation. The wound prepared aseptically and surgical debridement was carried out to remove pus and necrotic tissue on the plantar surface of both feet. Sample of the abscesses was collected aseptically and send for culture. Surgical dressing and bandage used to minimize pressure on digital foots and Clindamycin 1\% topical gel (Iran Najo Co. Tehran, Iran) also applied to plantar surface of both legs. Oxygen supplementation for several minutes used for recovery and then extubated.
Post surgical treatment was initiated with $50 \mathrm{mg} / \mathrm{kg}, 2$ times daily, IM Clindamycin (Darou Pakhsh Co., Iran) for 3 days and continued with $50 \mathrm{mg} / \mathrm{kg}, 2$ times daily, PO Clindamycin (Darou Pakhsh Co., Iran) for 11 days more. Additional supportive treatment included injection of $1 \mathrm{~mL}$ of Vitamin AD3E (Eurovet, Netherlands) and $0.7 \mathrm{ml}$ of Vitamin B1, B6, B12 (Neurobion ${ }^{\circledR}$, Merck, Germany) intramuscularly. The results of laboratory culture and isolation from drained pus demonstrated Staphylococcus aureus as of infectious organism in the bumblefoot and osteomyelitis.

After 14 days of treatment with Clindamycin a second blood sample revealed a normal Complete blood count and wound healed successfully. It was suggested to owner to use softer substrate and enforce more time on the water to avoid recurrence of FPD.

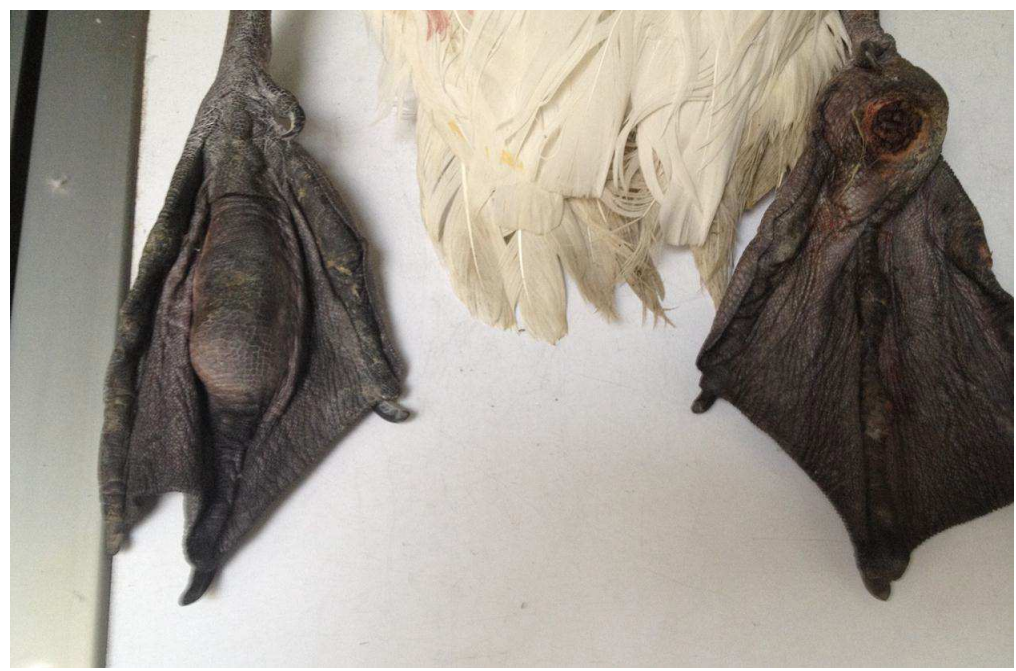

Fig. 1: Bumblefoot in a Mute Swan
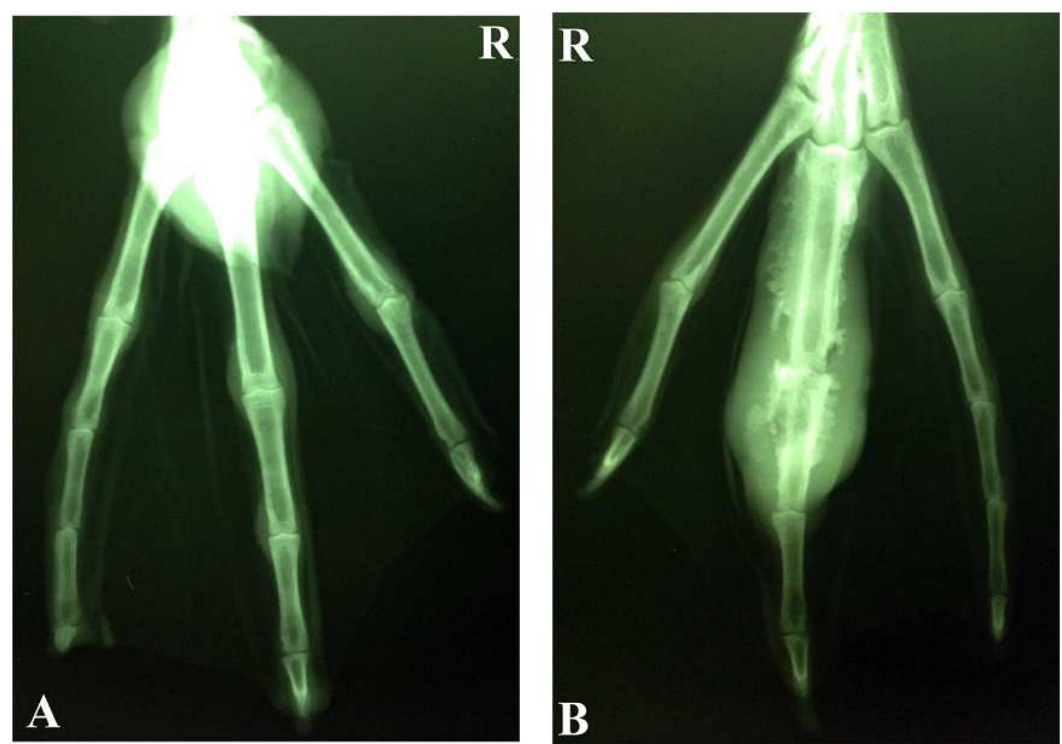

Fig. 2: A. dorso-plantar radiograph of right foot illustrating radiopaque area of plantar pododermatitis 


\section{Discussion}

FPD is a common husbandry condition of captivereared birds characterized by local injury to the integument of the foot (usually the digital or plantar metatarsal pads). Symptoms include scab formation, thickenings, swellings, inflammation and ulcerative lesions of the subcutaneous tissues of the foot pads and, in extreme cases, distortion of the digits and septic arthritis of the joints and osteomyelitis (Reissig et al., 2011).

The etiology of FPD includes a complex of environmental, host and bacterial components (Oaks, 1993). Potential or known predisposing factors contain species, trauma to the feet, poor nutritional status, deficiencies in vitamin A or vitamin E, heavy parasite load and poor hygiene (Halliwell and Graham, 1986; Remple and Al-ashbal, 1993).

FPD is a common condition in broilers and turkey. Some factors affect incidence of this problem, as Shepherd and Fairchild (2010) discussed, environmental factors, food and nutritional deficiencies, sex and body size could affect broilers and turkeys.

In environmental factors, one thing that is common among most previous research is that litter moisture is a significant factor in the onset of FPD. Continually standing in wet litter will reason the footpad to soften and become more prone to damage, predisposing the bird to developing FPD. Drying out the litter and moving birds from wet litter to dry litter was remarked to reverse the severity of FPD (Shepherd and Fairchild, 2010).

As a second environmental factor, season could affect the incidence of FPD in broilers. According to Mayne (2005), higher incidences of hock and breast lesions occurring during the winter months when analogize with summer months.

Deficiencies of vitamins and amino acids such as biotin, riboflavin, methionine and cystine in the diets of growing birds have been reported to affect the incidence of FPD. Diets deficient in biotin have begeted FPD lesions in turkeys Harms and Simpson (1977) suggested that biotin alone is not responsible for the occurrence of these lesions or that it is not effective in conditions that are known to directly increase the incidence and severity of FPD. Also Birds elevated on an all-vegetable diet had a higher incidence of FPD than did birds raised on a mixed animal and plant diet (Shepherd and Fairchild, 2010).

As a dietary consideration, electrolyte imbalance is important as Harms and Simpson (1977) found out that dietary salt content had a direct influence on the severity of footpad lesions and that dermatitis was more severe with higher levels of salt (Harms and Simpson, 1977).

Controversial statements existed about the correlation between sex and body weight and accretion of FPD, but according to Shepherd 2010 it is currently accepted that these factors are not significant contributors in the happening of FPD. About FPD in broilers and turkeys, we know, litter material and depth is an important area of research for the understanding and prevention of FPD (Shepherd and Fairchild, 2010).

In birds of prey, eagles and buteos were the species most affected by FPD. Their occurrence rates were significantly higher than those of other species; the median duration of bumblefoot was two to five times greater for these species (Rodriguez-Lainz et al., 1997).

In Müller et al. (2000) research in wild and captivebred falcons, diet shows a significant influence on the occurrence of FPD. Especially the wild falcons tested showed a reduced morbidity rate when fed pigeons, bustards and ducks, which resemble their usual prey. In contrast to this, captive-bred falcons are often fed with low-energy food like beef as part of their nutrition plan, resulting in a significant decrease of FPD cases (Müller et al., 2000).

Remple and Al-Ashbal (1993) stated that, the incidence of bumblefoot in free-living raptors is considered to be lower than in captive birds-probably because wild birds are more active, have more control over landing impact and have a choice of perching surfaces with a variety of textures.

There is little information available about incidence of FPD in waterfowl. But occurs most commonly in larger species such as swans due either to chronic wear, pressure and abrasion (especially when birds have to walk on hard surfaces such as concrete or tarmac) or following crash Landing on tarmac surfaces as can occur when birds confuse the shimmering surface of a road for a water surface (Humphreys, 1996).

In this reported mute swan, dietary deficiency, living on hard floor, poor hygiene and long time from onset of disease through to referral are predisposing factors of FPD associated with osteomyelitis.

Clindamycin, a chlorine-substituted derivative of lincomycin, is effective against gram-positive cocci and obligate anaerobes. Although clindamycin is considered a bacteriostatic drug, it can be bactericidal at high concentrations. In mammals, clindamycin is often used to treat periodontal disease and osteomyelitis. In avian medicine, birds with wounds and osteomyelitis are routinely treated with clindamycin alone or in combination with other antimicrobials (Lenarduzzi et al., 2011).

FPD is clinically resistant to therapy and frequently recurs, even after quiescent periods of weeks or years (Lenarduzzi et al., 2011). But in this mute swan no recurrence reported 6 months post-surgery. Full surgical debridement, effective antibiotics, good post-surgical care and husbandry are affecting factors that cause no recurs of disease despite osteomyelitis.

\section{Acknowledgement}

Thanks for all the friends who co-operated with us. 


\section{Author's Contributions}

Alireza Jahandideh: Participated in all experiments, coordinated the data-analysis and contributed to the writing of the manuscript.

Reihaneh Manouchehri: Participated in the department and control the treatment process and Collaborated on preparing the article.

Shiva Jahanshiri: Designed the research plan and organized the study and coordinated the mouse work.

Manely Ansari: Taked radiographs and referred for treatment.

\section{Ethics}

This article is original and contains unpublished material. The corresponding author confirms that all of the other authors have read and approved the manuscript and there are no ethical issues involved.

\section{References}

Burnie, D.K., 2011. Animal: The Definitive Visual Guide to the World's Wildlife. 1st Edn., Dorling Kindersley, London, UK, ISBN-10: 140539109X, pp: 632.

Daoust, P.Y., D. Wadowska, F. Kibenge, R.P. Campagnol and K.S. Latimer et al., 2000. Proliferative pododermatitis associated with virus-like particles in a northern gannet. J. Wildlife Dis., 36: 378-382. DOI: $10.7589 / 0090-3558-36.2 .378$

Doneley, R., 2010. Avian Medicine and Surgery in Practice. 1st Edn., Manson Publishing, London, UK, ISBN-10: 9781840765922, pp: 336.

Gentz, E.J., 1996. Fusobacterium necrophorum associated with bumblefoot in a wild great horned owl. J. Avian Med. Surg., 10: 258-261.

Halliwell, W.H. and D.L. Graham, 1986. Viral Diseases of Birds of Prey. In: Zoo and Wild Animal Medicine, Fowler, M.E. (Ed.), Philadelphia, Sanders, PA, USA: pp: 415-416.

Harms, R.H. and C.F. Simpson, 1977. Influence of wet litter and supplemental biotin on foot pad dermatitis in Turkey Poults. Poultry Sci., 56: 2009-2012. DOI: $10.3382 /$ ps.0562009

Humphreys, P.N., 1996. Wing and Leg Problems. In: BSAVA Manual of Raptors, Pigeons and Waterfowl. British Small Animal Veterinary Association, Beynon, P.H., N.A. Forbes and N.H. Harcourt-Brown (Eds.), Gloucestershire, UK, pp: 311-314.
Lenarduzzi, T., C. Langston and M.K. Ross, 2011. Pharmacokinetics of clindamycin administered orally to pigeons. J. Avian Med. Surg., 25: 259-265. DOI: $10.1647 / 2010-038.1$

Mayne, R.K., 2005. A review of the aetiology and possible causative factors of foot pad dermatitis in growing turkeys and broilers. Worlds Poultry Sci. J., 61: 256-267. DOI: 10.1079/WPS200458

Müller, M.G., U. Wernery and J. Kösters, 2000. Bumblefoot and lack of exercise among wild and captive-bred falcons tested in the United Arab Emirates. Avian Dis., 44: 676-680.

DOI: $10.2307 / 1593110$

Oaks, J.L., 1993. Immune and Inflammatory Responses in Falcon Staphylococcal Pododermatitis. In: Raptor Biomedicine, Redig, P.T., J.E. Cooper, J.D. Remple and D.B. Hunter (Eds.), University of Minnesota Press, Minnesota, USA, pp: 72-87.

Parsad, A., S.K. Shukhla, N. Arora and P. Kumar, 2010. Bumble foot in geese and its successful management. Vet. Pract., 11: 9-9.

Poorbaghi, S.L., M. Javdani and S. Nazifi, 2012. Surgical treatment of bumblefoot in a captive golden eagle (Aquila chrysaetos). Vet. Res. Forum, 3: 71-73. PMID: 25653750

Reidarson, T.H., J. Mcbain and L. Burch, 1999. A novel approach to the treatment of bumblefoot in penguins. J. Avian Med. Surg., 13: 124-127.

Reissig, E.C., D.M. Tompkins, R.F. Maloney, E. Sancha and D.A. Wharton, 2011. Pododermatitis in captivereared black stilts (Himantopus novaezelandiae). J. Zoo Wildlife Med., 42: 408-413.

DOI: $10.1638 / 2010-0215.1$

Remple, J.D. and A.A. Al-ashbal, 1993. Raptor Bumblefoot: Another Look at Histopathology and Pathogenesis. In: Raptor Biomedicine, Redig, P.T., J.E. Cooper, J.D. Remple and D.B. Hunter (Eds.), University of Minnesota Press, Minnesota, USA, pp: 92-98.

Rodriguez-Lainz, A.J., D.W. Hird, P.H. Kass and D.L. Brooks, 1997. Incidence and risk factors for bumblefoot (pododermatitis) in rehabilitated raptors. Preventive Vet. Med., 31: 175-184. DOI: $10.1016 / \mathrm{S} 0167-5877(96) 01137-3$

Routh, A., 2000. Veterinary care of the mute swan. BMJ, 22: 426-433. DOI: 10.1136/inpract.22.8.426

Shepherd, E.M. and B.D. Fairchild, 2010. Footpad dermatitis in poultry. Poultry Sci., 89: 2043-2051. DOI: $10.3382 /$ ps.2010-00770 